\title{
Adverse drug reactions in SARS-CoV-2 hospitalised patients: a case-series with a focus on drug-drug interactions
}

\author{
Giada Crescioli $i^{1,2} \cdot$ Valentina Brilli $^{1,3} \cdot$ Cecilia Lanzi $^{3} \cdot$ Andrea Burgalassi $^{1,3} \cdot$ Alessandra leri $^{3} \cdot$ Roberto Bonaiuti $^{1,4}$. \\ Elias Romano ${ }^{5,6} \cdot$ Rinaldo Innocenti $^{5} \cdot$ Guido Mannaioni $^{1,3} \cdot$ Alfredo Vannacci $^{1,2,4} \cdot$ Niccolò Lombardi $^{1,2,3}$ (1)
}

Received: 14 September 2020 / Accepted: 21 November 2020 / Published online: 23 December 2020

(c) The Author(s) 2020

\begin{abstract}
Due to the need of early and emergency effective treatments for COVID-19, less attention may have been paid to their safety during the global emergency. In addition, characteristics of drug-drug interaction (DDI)-related adverse drug reactions (ADRs) in COVID-19 patients have not yet been studied in depth. The aim of the present case-series study is to describe clinical and pharmacological characteristics of SARS-CoV-2 hospitalised patients, focusing on ADRs, particularly those related to DDIs. We evaluated all reports of COVID-19 medication-related ADRs collected within the COVID-19 Units of Careggi University Hospital, Florence (Italy), between January 1st and 31st May 2020. Information regarding COVID-19 medications, patients' demographic and clinical characteristics, concomitant drugs, ADRs description and outcome, were collected. Each case was evaluated for the causality assessment and to identify the presence of DDIs. During the study period, 23 Caucasian patients (56.5\% males, mean age 76.1 years) experienced one or more ADRs. The majority of them were exposed to polypharmacy and $17.4 \%$ presented comorbidities. ADRs were referred to cardiovascular, psychiatric and gastrointestinal disorders. The most frequently reported preferred term was QT prolongation (mean QT interval $496.1 \mathrm{~ms}$ ). ADRs improved or resolved completely in $60.8 \%$ of cases. For all patients, a case-by-case evaluation revealed the presence of one or more DDIs, especially those related to pharmacokinetic interactions. Despite the small number of patients, our evidence underline the clinical burden of DDIs in SARS-CoV-2 hospitalised patients and the risk of unexpected and uncommon psychiatric ADRs.
\end{abstract}

Keywords Drug-drug interactions · COVID-19 $\cdot$ Pharmacovigilance $\cdot$ Adverse drug reactions $\cdot$ Internal medicine

Alfredo Vannacci and Niccolò Lombardi are the co-last authors.

Supplementary Information The online version contains supplementary material available at https://doi.org/10.1007/s1173 9-020-02586-8.

Niccolò Lombardi

niccolo.lombardi@unifi.it

1 Department of Neurosciences, Psychology, Drug Research and Child Health, Section of Pharmacology and Toxicology, University of Florence, Florence, Italy

2 Tuscan Regional Centre of Pharmacovigilance, Florence, Italy

3 Toxicology Unit, Emergency Department, Careggi University Hospital, Florence, Italy

\section{Introduction}

Since the outbreak of COVID-19 epidemic, clinicians started a real "gold rush" to find the best therapeutic option among those currently available for infectious and inflammatory diseases [1]. Waiting for a vaccine, the study of COVID-19 clinical characteristics proved effective in directing towards meaningful medical choices.

4 Joint Laboratory of Technological Solutions for Clinical Pharmacology, Pharmacovigilance and Bioinformatics, University of Florence, Florence, Italy

5 Internal Medicine Unit 2, Emergency Department, Careggi University Hospital, Florence, Italy

6 Department of Experimental and Clinical Medicine, University of Florence, Florence, Italy 
Three main stages represent COVID-19 infection clinical course. In the first phase, the virus replicates within the host cells and patients may experience symptoms as dry cough, fever, and general weakness and malaise [2]. In the second phase, the progression of the disease is characterised by the development of a bilateral interstitial pneumonia and by morphological changes in host's lungs [3]. Respiratory symptoms, which could be stable in the first phase of pneumonia, could worsen, due to both direct effects of the virus and host's immune response, leading to clinical instability and severe hypoxemia [4]. Only in a limited number of cases (third phase), patients experience a "cytokine storm" and following hyper-inflammatory state, with local and systemic consequences [5]. Among them, at the lung level, are arterial and venous vasculopathy, with thrombosis of the small vessels and evolution towards serious and sometimes permanent lung lesions. A progressive alteration of inflammatory and coagulation parameters, such as C-reactive Protein (PCR), ferritin, pro-inflammatory cytokines, consumption of clotting factors, and increased levels of the fragments of fibrin degradation (D-dimer), have been observed $[6,7]$.

In this complex scenario, therapeutic strategies have focused on viral growth containment in the first and second phases of the disease, and on inflammation and coagulation control, in the second and third phases (Table 1) [8]. When COVID-19 pandemic spread to Italy, the Italian Medicines Agency (AIFA) approved the off-label use of the antiviral combinations lopinavir/ritonavir and darunavir/cobicistat,

Table 1 Indication of use and mechanism of action of principal SARS-CoV-2 medications in Italy

\begin{tabular}{|c|c|c|c|c|}
\hline $\begin{array}{l}\text { SARS-CoV-2 infection } \\
\text { phase }\end{array}$ & Medication & Indication & Mechanism of action & AIFA authorization \\
\hline \multirow[t]{4}{*}{$\begin{array}{l}\text { Phase I and II } \\
\text { Viral growth containment }\end{array}$} & $\begin{array}{l}\text { Darunavir/cobicistat } \\
\text { Lopinavir/ritonavir }\end{array}$ & HIV treatment & $\begin{array}{l}\text { Inhibition of viral replica- } \\
\text { tion by the binding and } \\
\text { inactivation of the 3CLpro } \\
\text { and PL2pro proteases }\end{array}$ & $\begin{array}{l}\text { Off-label use restricted to } \\
\text { RCTs (last update July } \\
\text { 17th, 2020) }\end{array}$ \\
\hline & $\begin{array}{l}\text { Hydroxychloroquine } \\
\text { Chloroquine }\end{array}$ & $\begin{array}{l}\text { Antimalarials, antirheumat- } \\
\text { ics }\end{array}$ & $\begin{array}{l}\text { Increasing of endosomal } \\
\mathrm{pH} \text { crucial for virus-cell } \\
\text { fusion }\end{array}$ & $\begin{array}{l}\text { Off-label use restricted to } \\
\text { RCTs (last update July } \\
\left.22^{\text {nd }}, 2020\right)\end{array}$ \\
\hline & Remdesivir* & Ebola virus & $\begin{array}{l}\text { In vitro and in vivo activity } \\
\text { against SARS-CoV-2, } \\
\text { MERS-CoV and SARS- } \\
\text { CoV }\end{array}$ & Compassionate use \\
\hline & Ribavirin* & $\begin{array}{l}\text { Chronic HCV and RSV } \\
\text { infections }\end{array}$ & $\begin{array}{l}\text { Guanosine analogue that } \\
\text { interferes with the replica- } \\
\text { tion of RNA and DNA } \\
\text { viruses }\end{array}$ & Compassionate use \\
\hline \multirow[t]{6}{*}{$\begin{array}{l}\text { Phase III } \\
\text { Inflammation and coagula- } \\
\text { tion control }\end{array}$} & Azithromycin & $\begin{array}{l}\text { Antibacterial for systemic } \\
\text { use }\end{array}$ & $\begin{array}{l}\text { Downregulation of adhe- } \\
\text { sion molecules of cell } \\
\text { surface, reduction of pro- } \\
\text { inflammatory cytokines } \\
\text { production }\end{array}$ & $\begin{array}{l}\text { Authorised out of RCTs only } \\
\text { in SARS-CoV-2 positive } \\
\text { adult patients with bacterial } \\
\text { infections (last update May } \\
\text { 5th, 2020) }\end{array}$ \\
\hline & Canakinumab* & $\begin{array}{l}\text { Arthritis, autoinflammatory } \\
\text { fever, Still's disease (IL-1 } \\
\beta \text { antibody) }\end{array}$ & $\begin{array}{l}\text { Reduction of SARS-CoV- } \\
\text { 2-induced pneumonia and } \\
\text { inflammation }\end{array}$ & Compassionate use \\
\hline & Enoxaparin & $\begin{array}{l}\text { Prophylaxis of venous } \\
\text { thromboembolism }\end{array}$ & $\begin{array}{l}\text { Containment of thrombotic } \\
\text { phenomena from the pul- } \\
\text { monary circulation }\end{array}$ & Off-label use \\
\hline & Tocilizumab & RA (IL-6 receptor antibody) & $\begin{array}{l}\text { Reduction of SARS-CoV- } \\
\text { 2-induced pneumonia and } \\
\text { inflammation }\end{array}$ & Off-label use \\
\hline & Ruxolitinib* & $\begin{array}{l}\text { Myelofibrosis (inhibitor of } \\
\text { JAK1 and JAK2 kinases) }\end{array}$ & $\begin{array}{l}\text { Reduction of SARS-CoV- } \\
\text { 2-induced pneumonia and } \\
\text { inflammation }\end{array}$ & Compassionate use \\
\hline & Solnatide* & $\begin{array}{l}\text { Pseudo-hypoaldosteronism } \\
\text { 1B }\end{array}$ & $\begin{array}{l}\text { In study to treat pulmonary } \\
\text { permeability oedema in } \\
\text { Austria and Germany }\end{array}$ & Compassionate use \\
\hline
\end{tabular}

AIFA Italian Medicines Agency, $C o V$ coronavirus, $H C V$ hepatitis virus C, HIV Human Immunodeficiency Viruses, MERS Middle East Respiratory Syndrome, $R A$ rheumatoid arthritis, $R C T$ randomised clinical trial, $R S V$ respiratory syncytial virus, $S A R S$ severe acute respiratory syndrome

*Compassionate use 
the use of antimalarials chloroquine and hydroxychloroquine (HCQ), the antibiotic azithromycin, and the anticoagulant enoxaparin [9]. Clinical experience also suggested the use of tocilizumab, a humanised monoclonal antibody against interleukin (IL)-6 receptor [10].

However, due to the need of early and emergency effective treatments for COVID-19, less attention may have been paid to their safety during the global emergency. From the beginning of COVID-19 pandemic, concerns about HCQ efficacy and safety raised [11] and subsequently AIFA suspended its use in SARS-CoV-2 patients out of clinical trials on May $29^{\text {th }}, 2020$ [12]. Moreover, based on available evidence concerning the efficacy and safety of fixed associations darunavir/cobicistat and lopinavir/ritonavir, AIFA also suspended their use out of clinical trials on July 17th 2020 [13, 14].

Prevalence of adverse drug reactions (ADRs) in COVID19 patients has not yet been deeply evaluated, but results from observational studies suggest that its frequency could be high in this population [15]. The majority of ADRs includes gastrointestinal and liver system disorders. Nevertheless, potential harmful ADRs should be closely monitored, and pharmacovigilance monitors', toxicologists' and clinical pharmacologists' support in COVID-19 Units should be carefully considered to better manage COVID-19 therapies [16]. In particular, good quality information regarding drug-drug interaction (DDI)-related ADRs are still lacking.

In this context, the aim of the present case-series study is to describe clinical and pharmacological characteristics of SARS-CoV-2 hospitalised patients, focusing on ADRs, particularly those related to DDIs.

\section{Methods}

In the present observational study, we considered and evaluated all reports of suspected ADRs collected in the COVID19 Units of Careggi University Hospital, Florence (Italy), between January 1st and 31st May, 2020. All suspected ADRs were collected from the clinical charts after a consultation performed by the Toxicology Unit on request of clinicians working in COVID-19 Units.

Following the Italian pharmacovigilance legislation [17], a multidisciplinary team composed by experts in pharmacovigilance (GC, AV, and NL) and clinical toxicology (VB, $\mathrm{CL}, \mathrm{AB}, \mathrm{AI}$, and $\mathrm{GM}$ ) provided their consultation and filled out the specific report form $[18,19]$, collecting information on: (1) patients' demographic characteristics (age, gender, ethnic group); (2) patients' clinical status; (3) suspected drugs and concomitant medications (for each one, administration route, therapy duration, dosages, and therapeutic indication were recorded); (4) ADR description; and (5) ADR outcome (improvement, complete resolution, unchanged or worsened event, resolution with sequelae, and death). A "suspected drug" is defined as a drug which is potentially associated with the observed ADR, while a "concomitant medication" is a drug the patient is exposed to at the time of ADR occurrence. A concomitant medication may not necessarily be associated to the ADR.

For each case included in the analysis, the experts performed a medical evaluation to assess the causality relationship between the suspected drugs and their related ADRs according to the Naranjo's scale [20]. Moreover, each case was evaluated with the aim of identifying the presence of DDIs, which may have contributed to ADRs. DDIs were identified using two different validated tools: (1) the open access Drug Interaction Checker [21], and (2) the drug interaction software IBM Micromedex ${ }^{\circledR}$ (Thomson Reuters Healthcare Inc., Greenwood Village, Colorado, United States), available online with restricted access. As reported in the IBM Micromedex ${ }^{\circledR}$ [22] and Drug Interaction Checker [21] tools, DDIs were classified as mild, moderate, or major, depending on their clinical impact on patient.

Suspected drugs and concomitant medications were classified according to the Anatomical Therapeutic Chemical (ATC) classification system. ADR description according to diagnosis and symptoms was coded using the Medical Dictionary for Regulatory Activities (MedDRA) and organised by Preferred Term (PT) [23, 24].

Data are presented as number and percentages or, for continuous variables, as mean and standard deviation (SD).

\section{Results}

Between January 1st and May 31st, 2020, among patients hospitalised in the COVID-19 Units of Careggi University Hospital, Florence (Italy), clinicians requested a consultation for a total of 23 patients who experienced 1 or more ADRs.

All patients were Caucasian with a mean age of 76.1 ( $\mathrm{SD} \pm 14.4$ ) years. $56.5 \%$ of them were males, and the majority ( $82.6 \%$ ) were elderly (age $\geq 65$ years). All patients $(n=23)$ were exposed to more than one suspected drug. In $56.5 \%(n=13)$ of cases, more than three suspected medications were reported. Overall, $69 \%(n=16)$ of patients were treated with more than six concomitant medications, and $17.4 \%(n=4)$ presented more than six comorbidities. ADRs improved or resolved completely in $60.8 \%$ of cases, and were probably or possibly related to suspected drugs for all patients (Table 2).

According to Careggi University Hospital's standard procedures in use at the time of the survey, all SARS-CoV-2 hospitalised patients were administered with HCQ $800 \mathrm{mg}$ for the first day, followed by $400 \mathrm{mg} /$ daily for 5-7 days, alone or in association to lopinavir/ritonavir 400/100 mg twice/daily for 7-14 days. Clinicians could add azithromycin 
Table 2 Patients' characteristics

\begin{tabular}{|c|c|}
\hline Cases characteristics & No. of cases $N=23(\%)$ \\
\hline \multicolumn{2}{|l|}{ Patient age, years } \\
\hline $19-64$ & $4(17.4)$ \\
\hline $65-79$ & $5(21.7)$ \\
\hline$\geq 80$ & $14(60.9)$ \\
\hline Mean \pm standard deviation & $76.1 \pm 14.40$ \\
\hline \multicolumn{2}{|l|}{ Gender } \\
\hline Male & $13(56.5)$ \\
\hline Female & $10(43.5)$ \\
\hline \multicolumn{2}{|l|}{ No. of suspected drugs } \\
\hline 2 & $10(43.5)$ \\
\hline 3 & $8(34.8)$ \\
\hline$\geq 4$ & $5(21.7)$ \\
\hline \multicolumn{2}{|l|}{ No. of concomitant medications } \\
\hline None & $3(13.2)$ \\
\hline $1-5$ & $4(17.4)$ \\
\hline $6-10$ & $11(47.7)$ \\
\hline$\geq 11$ & $5(21.7)$ \\
\hline \multicolumn{2}{|l|}{ No. of comorbidities } \\
\hline None & $5(21.7)$ \\
\hline $1-5$ & $14(60.9)$ \\
\hline$\geq 6$ & $4(17.4)$ \\
\hline \multicolumn{2}{|l|}{ Outcome } \\
\hline Improvement & $14(60.8)$ \\
\hline Death & $5(21.7)$ \\
\hline Unchanged or worsened event & $3(13.2)$ \\
\hline Complete resolution & $1(4.3)$ \\
\hline \multicolumn{2}{|l|}{ Causality assessment } \\
\hline Certain & - \\
\hline Probable & $17(73.9)$ \\
\hline Possible & $6(26.1)$ \\
\hline Not classifiable & - \\
\hline \multicolumn{2}{|l|}{ QT prolongation (19 patients), ms } \\
\hline Mean \pm standard deviation & $496.1 \pm 36.64$ \\
\hline
\end{tabular}

(500 $\mathrm{mg}$ for the first day, followed by $250 \mathrm{mg} / \mathrm{daily}$ for 3-4 days) or darunavir/cobicistat ( $800 / 150 \mathrm{mg} /$ daily) to $\mathrm{HCQ}$, according to patient's needs. Patients received enoxaparin at the dosage of 4000 or 8000 International Unit (IU)/ daily based on their body weight and the presence of thromboembolic risk factors, such as Sepsis-Induced Coagulopathy (SIC) score $\geq 4$, neoplasia, central venous catheter, D-dimer levels $>1000 \mathrm{ng} / \mathrm{mL}$, Continuous Positive Airway Pressure (CPAP) or history of venous thromboembolism.

Table 3 shows a case-by-case description of evaluated ADR reports. One patient presented an elevation of transaminases, 3 patients experienced gastrointestinal (GI) ADRs (nausea, diarrhoea, vomiting and GI pain), 18 patients showed cardiovascular (CV) ADRs (ECG QT prolongation), 1 patient presented a prolongation of the $\mathrm{QT}$ interval along with symptoms of major depression, and 1 patient reported psychotic symptoms. The 19 patients who experienced an ECG QT prolongation showed a mean prolongation of QT interval of $496.1(\mathrm{SD} \pm 14.4) \mathrm{ms}$ (Table 2).

Table 4 shows all moderate and major DDIs observed in our sample between COVID-19 treatments and patients' concomitant medications. The application of tools for interactions revealed that all patients presented at least one DDI. Among 82 different DDIs, 53 (64.4\%) were moderate, and $32(39 \%)$ increased the risk of QT prolongation. Many others DDIs $(n=112)$ were identified between medications other than COVID-19 treatments (Supplementary Table 1).

\section{Discussion}

This study aimed to describe the clinical and pharmacological characteristics of SARS-CoV-2 hospitalised patients who experienced one or more ADRs, with a focus on DDIs. Based on the evidence herein reported, the majority of ADRs occurred in elderly patients exposed to polypharmacy.

Off-label drug utilisation and DDIs are well known causes of ADRs in the general population [25], and the risk of DDI-related ADRs typically increases in patients exposed to $c$ drugs, such as those aged $\geq 65$ years [24]. In the case of COVID-19 pandemic, lacking of specific pharmacological treatments forced clinicians and regulatory agencies to resort to currently available drugs. Thus, off-label drug utilisation could not be avoided. On the contrary, a patient's complete anamnesis, in particular regarding comorbidities and concomitant medications, may help in avoiding the occurrence of ADRs, often due to DDIs.

In our sample, according to the case-by-case clinical evaluation, most frequently reported ADRs were cardiac, psychiatric and nervous system, and gastrointestinal and hepatic disorders.

\section{Cardiac disorders}

We observed 19 cases of CV ADRs, in particular "QT prolongation". In these cases, the most frequently reported suspected COVID-19 medications were HCQ, azithromycin, lopinavir/ritonavir and darunavir/cobicistat, which are, based on their pharmacokinetic and pharmacodynamic properties, commonly associated to $\mathrm{CV}$ events.

HCQ acute toxicity occurs most frequently when therapeutic or high doses are administered rapidly through parenteral routes. HCQ doses of $>5 \mathrm{~g}$ given parenterally usually are fatal. Toxic manifestations relate primarily to the $\mathrm{CV}$ system, including hypotension, suppressed myocardial function, arrhythmias, and eventual cardiac arrest. Due to its long elimination half-life ( $>40$ days) [26], prolonged treatment with high doses may also cause ADRs such as widening of 


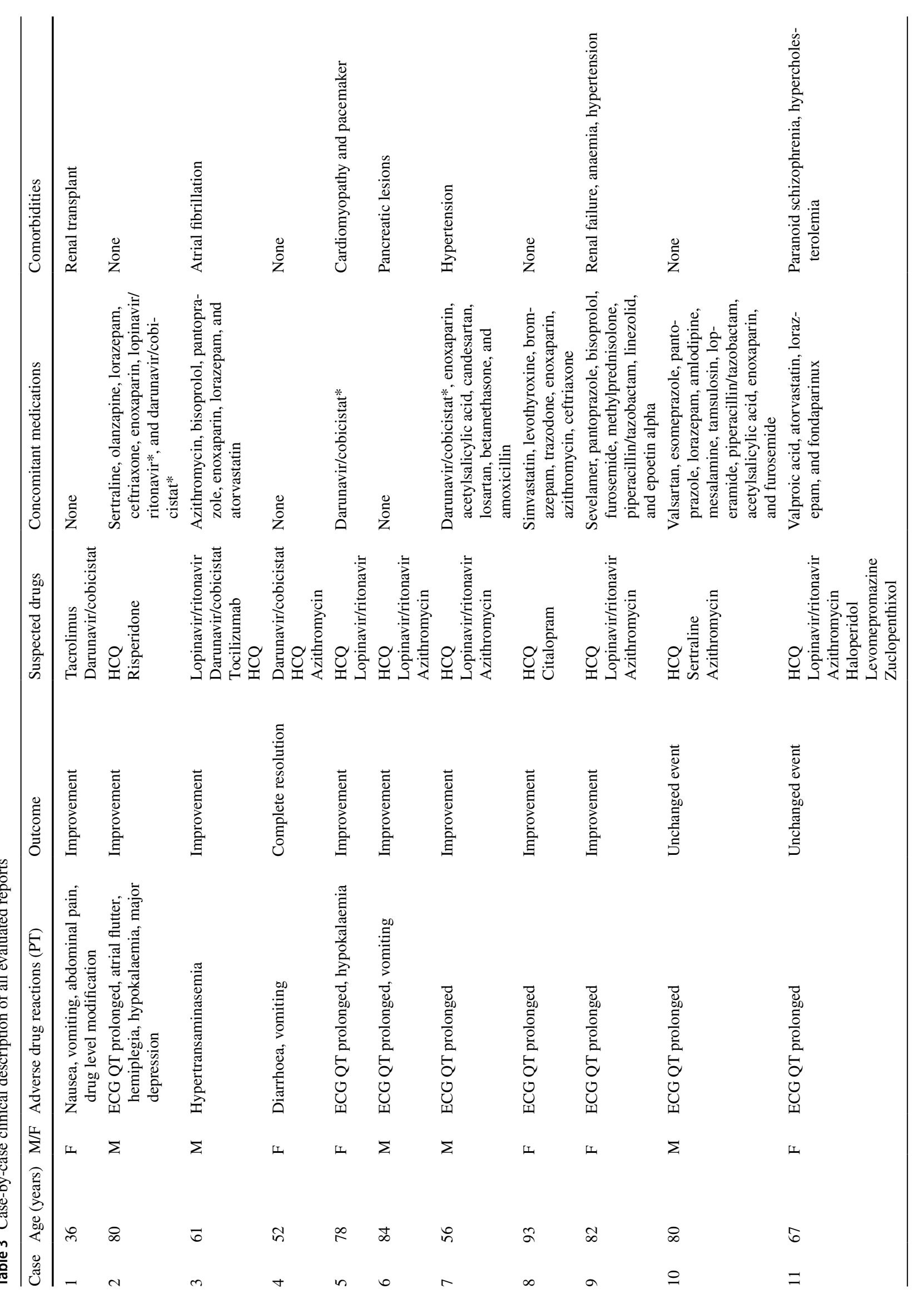




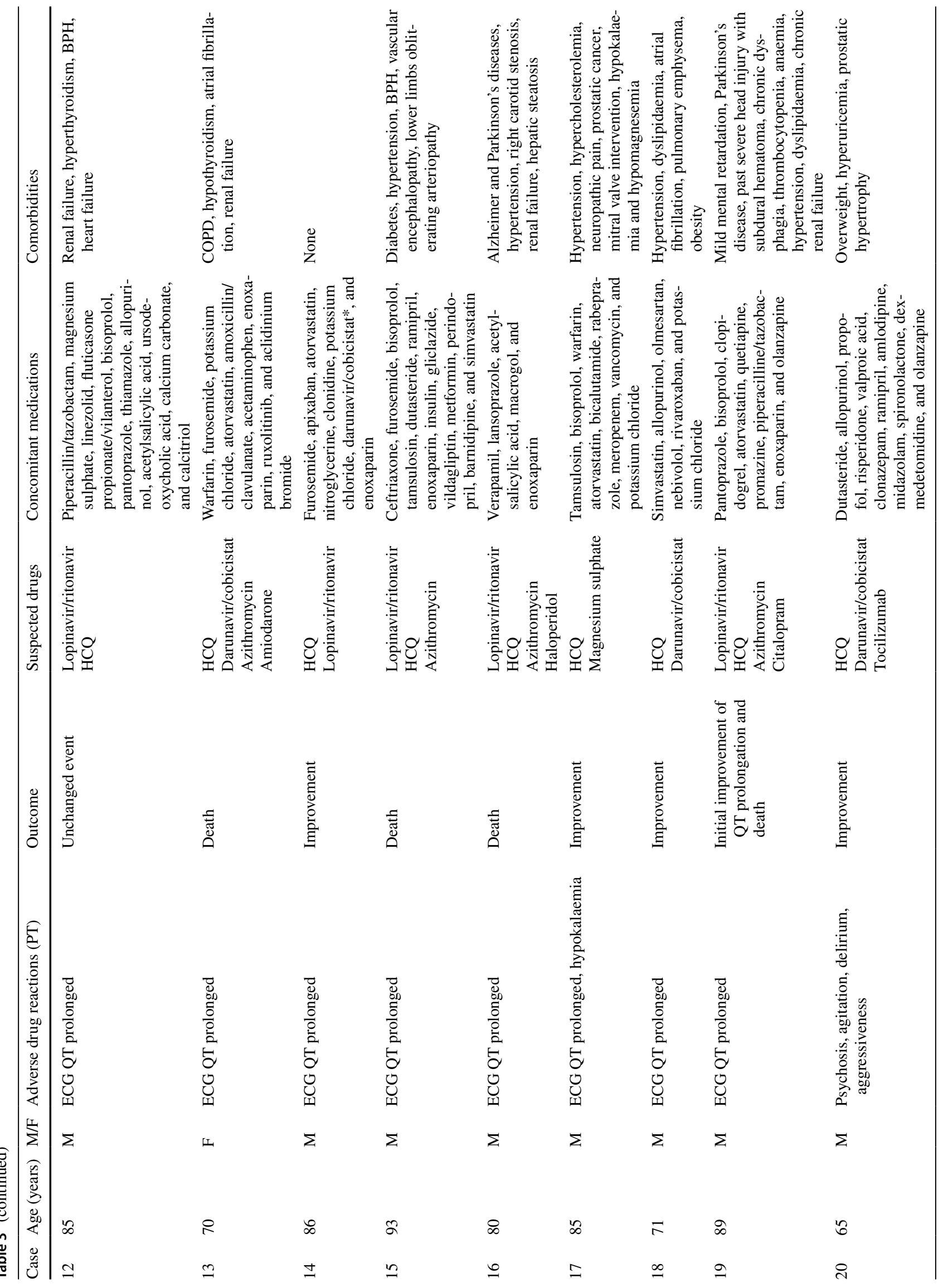




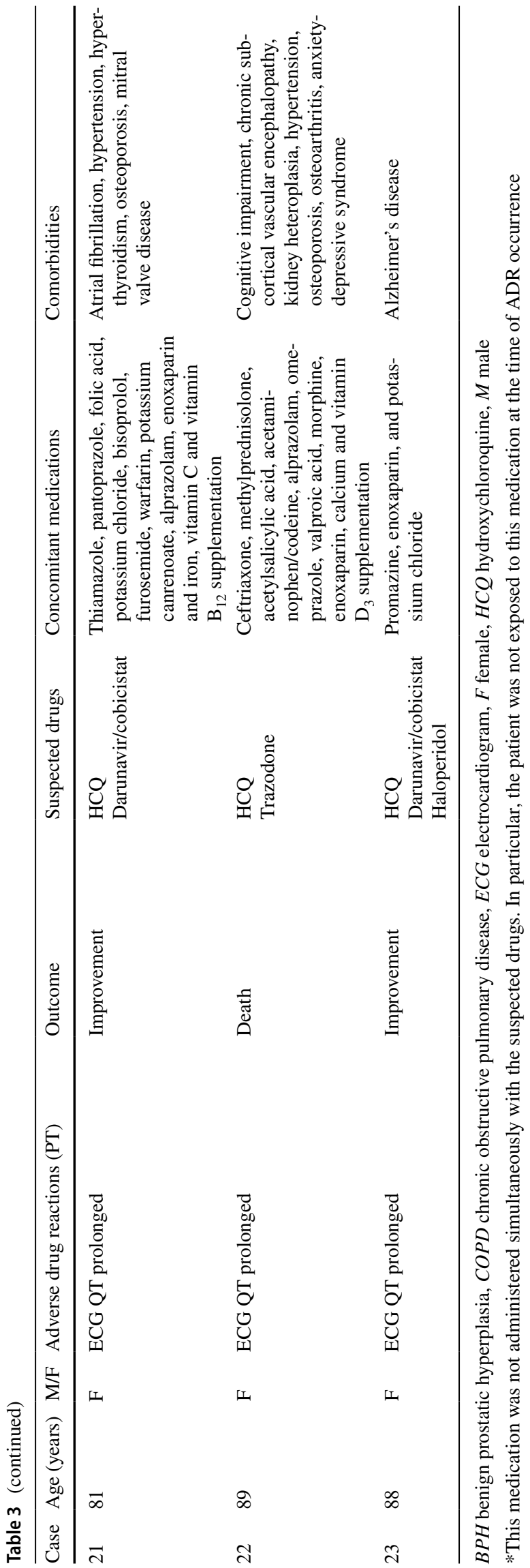

the QRS interval, and T-wave abnormalities. In fact, it is well known that HCQ inhibits human ether-a-go-go-related gene (hERG) potassium channels. Inhibition of hERG can block the outward flow of potassium, which leads to intracellular accumulation of potassium and ventricular repolarization and results in QT prolongation and torsade de pointes (TdP) [27]. These complications usually disappear shortly after the drug withdrawal. HCQ may also inhibit CYP2D6, interacting with a variety of different COVID-19 and nonCOVID-19 medications.

The macrolide azithromycin is a weak inhibitor of CYP3A4. In this case, in connection with its effect on QT prolongation, the potential for DDIs is associated to azithromycin pharmacodynamic characteristics. As such, caution should always be observed when combining azithromycin with other molecules that increase the QT interval, such as HCQ. In particular, QT prolongation seems to be significantly higher in patients who received the two medications concomitantly [28]. The exact mechanism by which azithromycin and other macrolides prolong the QT interval is through a blockade of the rapid component, $\mathrm{IKr}$, of the delayed rectifier potassium current IK, which is encoded by the hERG [29], similarly to HCQ.

Special caution must be used when administering protease inhibitors, such as lopinavir/ritonavir, due to their potential of inducing QT interval prolongation, particularly when used in combination with other pro-arrhythmic medications, such as HCQ and azithromycin. In fact, lopinavir/ ritonavir may increase concentrations of the co-administered medicinal products and this may result in an increase of their associated cardiac ADRs. This can be explained by the ability of lopinavir/ritonavir to modulate enzymes, in particular CYP3A4 and P-glycoprotein (P-gp). Lopinavir/ritonavir may also inhibit BCRP and OATP1B1 transporters [30]. These pharmacokinetic characteristics were also observed for darunavir/cobicistat [31], leading to a comparable profile in terms of DDIs and potentially related CV ADRs.

In general, attention should be exercised when COVID19 treatments are combined with drugs known to increase the PR or QT intervals, as they also cause conduction and repolarization disorders by themselves. Considering that QT prolongation could be an asymptomatic and potentially fatal event, it should be always strictly monitored. The risk factors for QT prolongation and TdS are female sex, older age, heart disease, exposure to QT interval prolonging drugs or metabolic inhibitors, bradycardia, and electrolyte disturbance [28]. The cornerstone of the management of acquired QT prolongation includes the identification and discontinuation of any suspected drug and the prompt correction of any metabolic abnormalities [32]. Short-term treatment includes the administration of intravenous magnesium sulphate and potassium chloride to manage a possible hypomagnesemia 


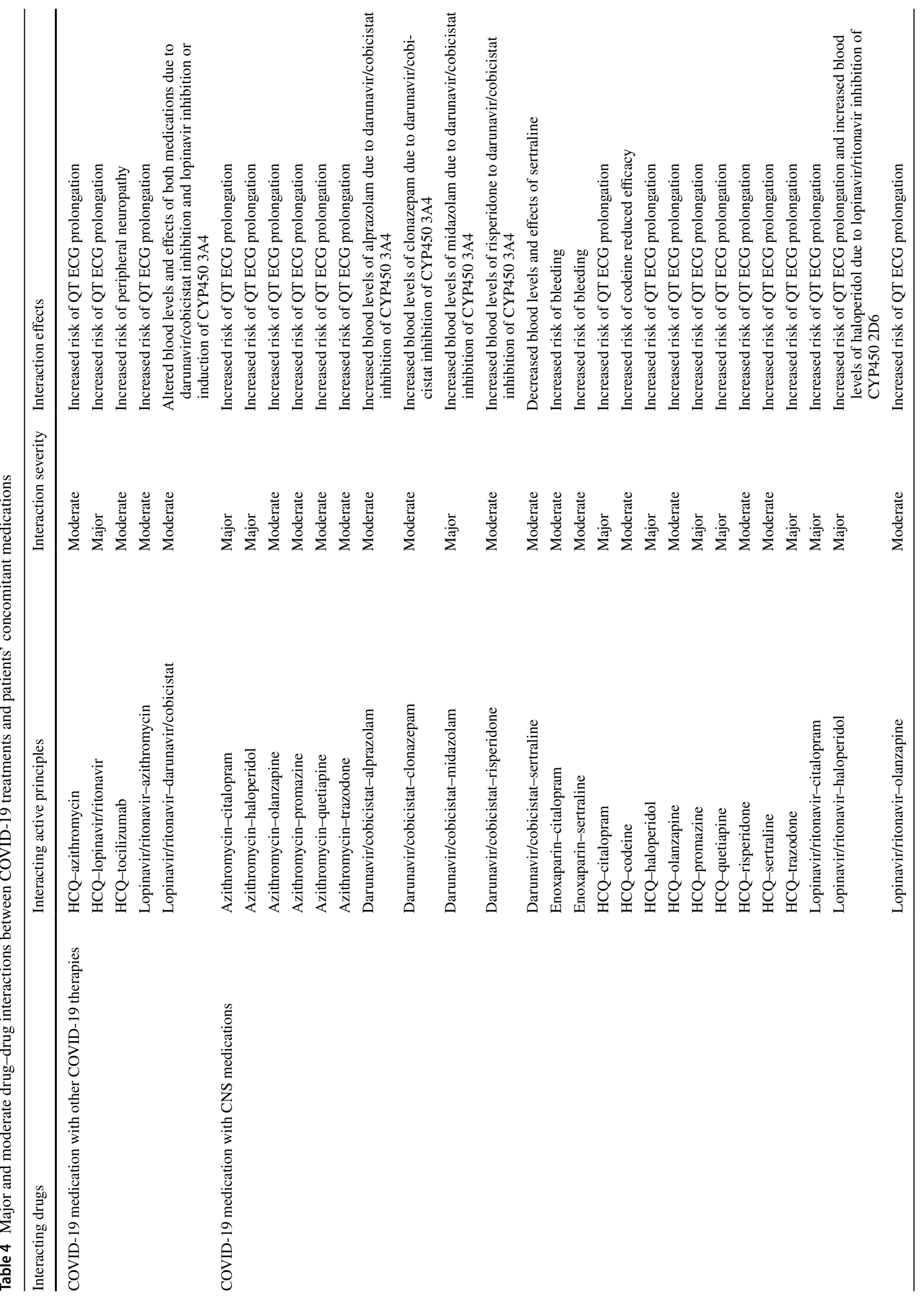




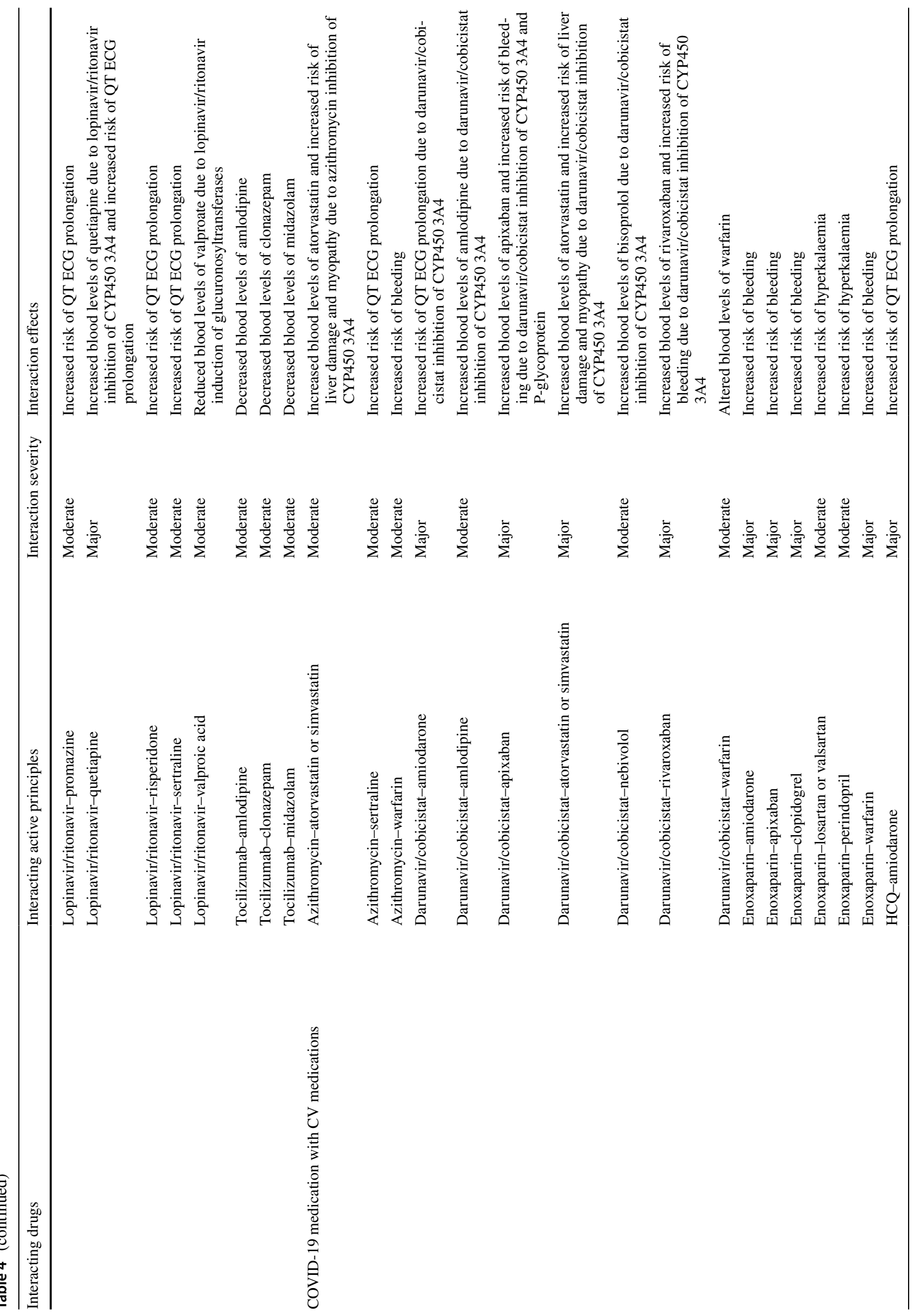




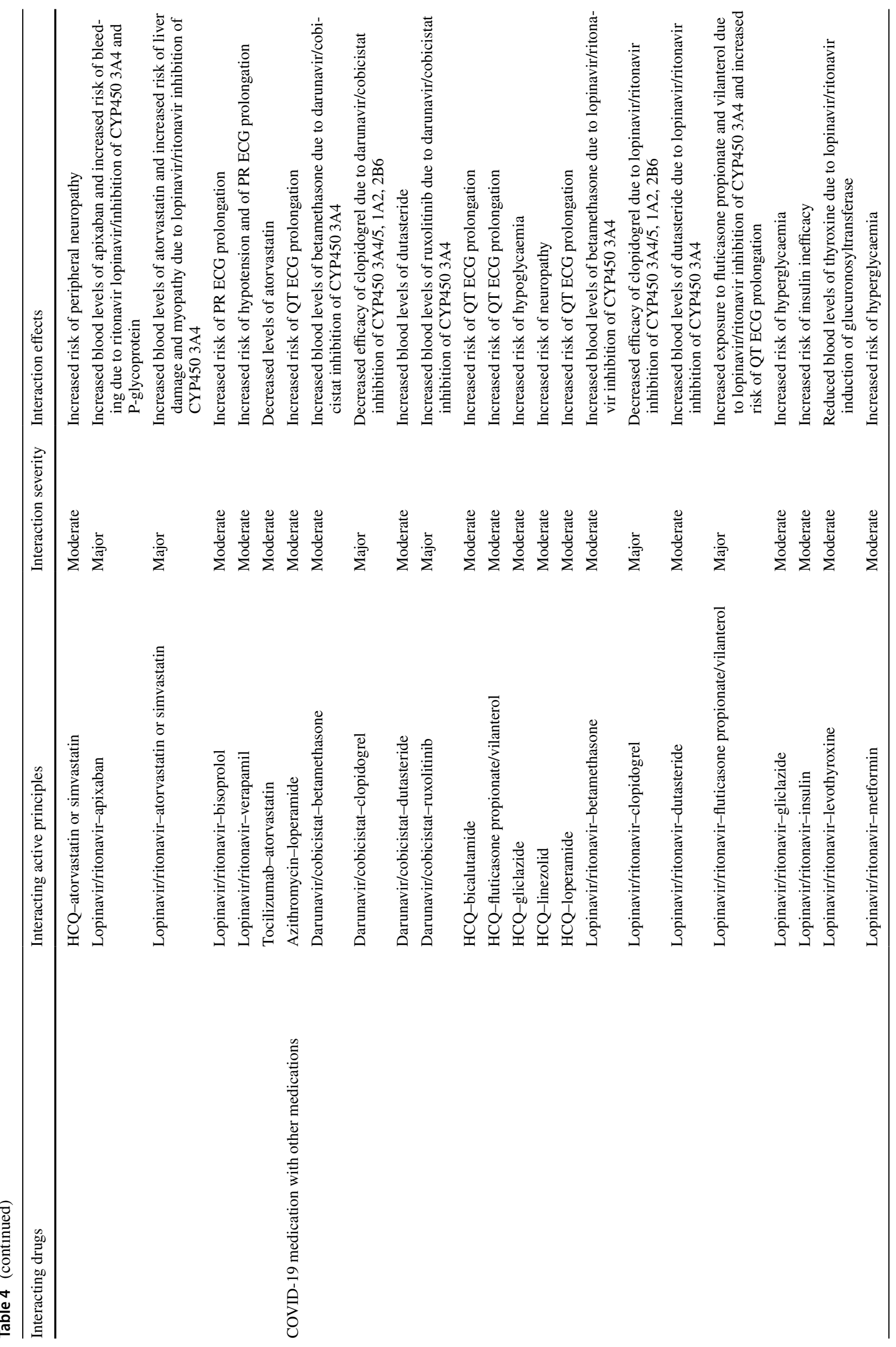


or hypokalemia. Thus, ECG and serum potassium levels should be frequently checked.

\section{Psychiatric and nervous system disorders}

We observed two cases of psychiatric disorders, in particular "major depression syndrome" and "psychotic crisis", accompanied by agitation, delirium, and aggressiveness. In these cases, the suspected COVID-19 medications were HCQ, darunavir/cobicistat, and, for one patient, tocilizumab. Considering the presence of co-administered antidepressants, antipsychotics, and hypnotic and sedative agents, for these patients a COVID-19 drug-related reduction of the activity of central nervous system medications could not be excluded. At the same time, psychological and social distress linked to COVID-19 infection should be taken into consideration [33, 34]. In fact, a recent systematic review and metaanalysis confirmed that SARS-CoV-2 might cause depression, anxiety, neuropsychiatric syndromes, and delirium in a significant proportion of patients in the acute stage [35]. Of notice, psychiatric ADRs are not commonly associated to HCQ [36], darunavir/cobicistat [37], and tocilizumab [38].

Cases of episodes of manic behaviour with psychotic features, persecutory delusions, anxiety, and reality detachment triggered by chloroquine were described [39-43]. Considering that HCQ and chloroquine have similar pharmacological properties, their toxicity profiles could be considered comparable. A meta-analysis [44] and a pharmacovigilance study on registry [45] confirmed the association between HCQ and psychiatric events. The mechanisms responsible for the psychiatric ADRs following HCQ exposure are not fully clarified. Among proposed hypotheses, there are the cholinergic imbalance related to the inhibition of acetylcholinesterase, prostaglandin E antagonism, the accumulation of HCQ toxic metabolites in lysosomes, and the down-regulation of glycoprotein-P in the blood-brain barrier [46]. Moreover, HCQ seems to inhibit the serotonin transporter, increasing its levels in the synapsis, and to act as $N$-methyl-D-aspartate agonist and $\gamma$-aminobutyric acid antagonist [46]. In general, psychiatric ADRs resolution follows HCQ withdrawal.

Among psychiatric ADRs, only "abnormal dreams" are reported in darunavir/cobicistat summary of product characteristics (SPC) [37], and, to date, the literature is lacking evidence on this topic. In general, protease inhibitors have limited central nervous system penetration, and therefore, less-pronounced neurological and psychiatric ADRs [47]. Among this group, ritonavir alone or in combination is more likely to produce psychiatric ADRs, in particular mood changes, agitation, and anxiety. In a clinical trial, HIV patients were randomised to darunavir/ritonavir or darunavir/ritonavir in combination with two nucleoside/nucleotide reverse transcriptase inhibitors [48]. After 48 weeks of therapy, grade 1-4 nervous system and psychiatric ADRs 
were seen in $16 \%$ and $9 \%$ of patients in each treatment arm. Researchers reported the following psychiatric manifestations: anxiety, depression, obsessive-compulsive disorder, and psychotic crisis. Considering that cobicistat is a CYP3A4 inhibitor and recommendations reported in its SPC suggest reducing the dosages of concomitant central nervous system medications, actually, there is no possibility of a drug therapeutic failure of antipsychotics driven by the pharmacokinetic properties of suspected protease inhibitors. Therefore, psychiatric ADRs observed in our sample may have been mainly related to high-dose HCQ and to underlying psychiatric comorbidities.

After a literature search, we ascertained the lack of evidence on psychiatric ADRs related to tocilizumab [38]. Nowadays, the association between tocilizumab and psychiatric ADRs cannot be fully explained. As for protease inhibitors, particularly darunavir/cobicistat, psychiatric ADRs may have been mainly related to high-dose HCQ and to pre-existing psychiatric disorders.

When diagnosis of a psychiatric ADRs is made, the best solution is to discontinue any suspected drug. Based on our clinical experience, depending on psychiatric clinical manifestation and on QT interval values, the administration of specific antipsychotic medications (i.e. chlorpromazine) could be considered. Usually, patient's mental status reverts to normal in a few days. In case of emergencies, emotional distress is ubiquitous, but some groups may be more vulnerable than others. In particular, people at heightened risk for COVID-19, those who contract the disease, and people with pre-existing medical or psychiatric conditions are at increased risk for adverse psychosocial outcomes [49]. Particular attention should also be given to mental health of people in conditions of increased risk, such as women during pregnancy [50] or post-partum [51].

\section{Gastrointestinal and hepatic disorders}

We observed four cases of GI and hepatic disorders, in particular "nausea", "vomiting", "diarrhoea" and "hypertransaminasemia". In these cases, all classes of COVID-19 medications were involved and GI intolerance often led to pharmacological switching between the associations lopinavir/ritonavir and darunavir/cobicistat. This kind of non-specific ADRs is frequently (common or very common) observed for all medication classes, including that of COVID-19 treatments [30, 36-38, 52]. The evaluation of causality assessment for GI and hepatic disorders must take into consideration the presence of concomitant medications and the underlying SARS-CoV-2 infection, which is commonly associated with GI symptoms [53].

\section{Conclusion}

Despite the small number of patients, the evidence reported in the present analysis confirms that the clinical burden of DDIs in SARS-CoV-2 hospitalised patients is relevant. Moreover, the risk of unexpected and uncommon ADRs, such those referred to psychiatric disorders, was highlighted. In this population, COVID-19 treatments should be used with extreme caution, especially in fragile and polymedicated patients. Although living in the context of a global emergency and looking for an effective therapeutic treatment, drug safety should never be overlooked, especially in the presence of DDIs.

Funding Open access funding provided by Università degli Studi di Firenze within the CRUI-CARE Agreement.

\section{Compliance with ethical standards}

Conflict of interest The authors report no relationships that could be construed as a conflict of interest.

Human and animal rights This article does not contain any study with human and animals performed by any of the authors.

Informed consent Not applicable.

Open Access This article is licensed under a Creative Commons Attribution 4.0 International License, which permits use, sharing, adaptation, distribution and reproduction in any medium or format, as long as you give appropriate credit to the original author(s) and the source, provide a link to the Creative Commons licence, and indicate if changes were made. The images or other third party material in this article are included in the article's Creative Commons licence, unless indicated otherwise in a credit line to the material. If material is not included in the article's Creative Commons licence and your intended use is not permitted by statutory regulation or exceeds the permitted use, you will need to obtain permission directly from the copyright holder. To view a copy of this licence, visit http://creativecommons.org/licenses/by/4.0/.

\section{References}

1. Chibber P, Haq SA, Ahmed I, Andrabi NI, Singh G (2020) Advances in the possible treatment of COVID-19: a review. Eur J Pharmacol 16:173372

2. Zhang XY, Huang HJ, Zhuang DL, Nasser MI, Yang MH, Zhu P et al (2020) Biological, clinical and epidemiological features of COVID-19, SARS and MERS and AutoDock simulation of ACE2. Infect Dis Poverty 9(1):99

3. Cui N, Zou X, Xu L (2020) Preliminary CT findings of coronavirus disease 2019 (COVID-19). Clin Imaging 65:124-132

4. Huang C, Wang Y, Li X, Ren L, Zhao J, Hu Y et al (2020) Clinical features of patients infected with 2019 novel coronavirus in Wuhan, China. Lancet (London, England) 395(10223):497-506

5. Jamwal S, Gautam A, Elsworth J, Kumar M, Chawla R, Kumar P (2020) An updated insight into the molecular pathogenesis, secondary complications and potential therapeutics of COVID-19 pandemic. Life Sci 17(257):118105 
6. Arachchillage DRJ, Laffan M (2020) Abnormal coagulation parameters are associated with poor prognosis in patients with novel coronavirus pneumonia. J Thrombosis Haemostasis: JTH 18(5):1233-1234

7. Tang N, Bai H, Chen X, Gong J, Li D, Sun Z (2020) Anticoagulant treatment is associated with decreased mortality in severe coronavirus disease 2019 patients with coagulopathy. J Thrombosis Haemostasis: JTH 18(5):1094-1099

8. Chen ZR, Zhou Y, Liu J, Peng HW, Zhou J, Zhong HL et al (2020) Pharmacotherapics advice in guidelines for COVID-19. Front Pharmacol 11:950

9. AIFA (2020) Farmaci utilizzabili per il trattamento della malattia COVID-19. https://www.aifagovit/aggiornamento-sui-farma ci-utilizzabili-per-il-trattamento-della-malattia-covid19. Last accessed: 04 August 2020

10. Rossotti R, Travi G, Ughi N, Corradin M, Baiguera C, Fumagalli $R$, et al. (2020) Safety and efficacy of anti-il6-receptor tocilizumab use in severe and critical patients affected by coronavirus disease 2019: a comparative analysis. J Infect

11. Vinetz JM (2020) Lack of efficacy of hydroxychloroquine in covid-19. BMJ (Clinical research ed) 19(369):m2018

12. AIFA (2020) Idrossiclorochina nella terapia dei pazienti adulti con COVID-19. https://www.aifagovit/documents/20142/1123276/ idrossiclorochina_22072020pdf/764add8f-f08f-0e26-df75-95298 6e54b8b. Last accessed: 04 August 2020

13. AIFA (2020) Darunavir/cobicistat nella terapia dei pazienti adulti con COVID-19. https://www.aifagovit/documents/20142/11232 76/darunavir_cobicistat_17072020pdf/6e34d1cf-9d14-4e018229-6467de2da082. Last accessed: 04 August 2020

14. AIFA (2020) Lopinavir/ritonavir nella terapia dei pazienti adulti con COVID-19. https://www.aifagovit/documents/20142/11232 76/lopinavir_ritonavir_17072020pdf/ab9e07d8-585b-6eda-0007a8f3d1e175c4. Last accessed: 04 August 2020

15. Sun J, Deng X, Chen X, Huang J, Huang S, Li Y, et al. (2020) Incidence of adverse drug reactions in COVID-19 patients in China: an active monitoring study by hospital pharmacovigilance system. Clin Pharmacol Therapeutics

16. Tuccori M, Convertino I, Ferraro S, Cappello E, Valdiserra G, Focosi D et al (2020) The impact of the COVID-19 "Infodemic" on drug-utilization behaviors: implications for pharmacovigilance. Drug Saf 43(8):699-709

17. Mazzitello C, Esposito S, De Francesco AE, Capuano A, Russo E, De Sarro G (2013) Pharmacovigilance in Italy: an overview. J Pharmacol Pharmacother 4(Suppl 1):S20-S28

18. Lombardi N, Crescioli G, Bettiol A, Marconi E, Vitiello A, Bonaiuti R et al (2018) Characterization of serious adverse drug reactions as cause of emergency department visit in children: a 5-years active pharmacovigilance study. BMC Pharmacol Toxicol 19(1): 16

19. Lombardi N, Crescioli G, Bettiol A, Tuccori M, Rossi M, Bonaiuti $\mathrm{R}$ et al (2019) Vaccines safety in children and in general population: a pharmacovigilance study on adverse events following anti-infective vaccination in Italy. Front Pharmacol 10:948

20. Naranjo CA, Busto U, Sellers EM, Sandor P, Ruiz I, Roberts EA et al (1981) A method for estimating the probability of adverse drug reactions. Clin Pharmacol Ther 30(2):239-245

21. Drug Interactions Checker. https://www.drugscom/interaction/ list/?drug_list. Last accessed: 04 August 2020

22. IBM Micromedex ${ }^{\circledR}$. https://www.micromedex solutionscom/ micromedex2/4340/WebHelp/Tools/Interactions/Drug_Interactio ns_severity_definitionshtm. Last accessed: 04 August 2020

23. Lombardi N, Bettiol A, Crescioli G, Ravaldi C, Bonaiuti R, Venegoni M, et al. (2020) Risk of hospitalisation associated with benzodiazepines and z-drugs in Italy: a nationwide multicentre study in emergency departments. Internal Emergency Med
24. Lombardi N, Crescioli G, Bettiol A, Tuccori M, Capuano A, Bonaiuti R et al (2020) Italian emergency department visits and hospitalizations for outpatients' adverse drug events: 12-year active pharmacovigilance surveillance (The MEREAFaPS Study). Front Pharmacol 11:412

25. Hult S, Sartori D, Bergvall T, Hedfors Vidlin S, Grundmark B, Ellenius J et al (2020) A feasibility study of drug-drug interaction signal detection in regular pharmacovigilance. Drug Saf 43(8):775-785

26. Laurence L. Brunton BAC, Bjorn C. Knollman (2011) Quinolines and related compounds. In: Brunton LL, (ed). Goodman and Gilman's the pharmacological basis of therapeutics, Twelfth Edition 12th Edition. New York: McGraw-Hill Companies; p. Chapter 49; pp 1270-2

27. Venisse N (2020) Potential drug-drug interactions associated with drugs currently proposed for COVID-19 treatment in patients receiving other treatments. Fundamental Clin Pharmacol

28. Kelly M, O'Connor R, Townsend L, Coghlan M, Relihan E, Moriarty M, et al. (2020) Clinical outcomes and adverse events in patients hospitalised with COVID-19, treated with off-label hydroxychloroquine and azithromycin. Br J Clin Pharmacol

29. Lu ZK, Yuan J, Li M, Sutton SS, Rao GA, Jacob S et al (2015) Cardiac risks associated with antibiotics: azithromycin and levofloxacin. Expert Opinion Drug Safety 14(2):295-303

30. EMA. Kaletra-Annex I-Summary of product characteristics. https://www.emaeuropaeu/en/documents/product-information/ kaletra-epar-product-information_enpdf. Last accessed: 04 August 2020

31. EMA. Prezista-Annex I-Summary of product characteristics. https://www.emaeuropaeu/en/documents/product-informatio n/prezista-epar-product-information_enpdf. Last accessed: 04 August 2020

32. Kallergis EM, Goudis CA, Simantirakis EN, Kochiadakis GE, Vardas PE (2012) Mechanisms, risk factors, and management of acquired long QT syndrome: a comprehensive review. Sci World J 2012:212178

33. Rajkumar RP (2020) COVID-19 and mental health: a review of the existing literature. Asian J Psychiatry 10(52):102066

34. Tandon R (2020) The COVID-19 pandemic, personal reflections on editorial responsibility. Asian J Psychiatry 50:102100

35. Rogers JP, Chesney E, Oliver D, Pollak TA, McGuire P, FusarPoli P et al (2020) Psychiatric and neuropsychiatric presentations associated with severe coronavirus infections: a systematic review and meta-analysis with comparison to the COVID-19 pandemic. Lancet Psychiatry 7(7):611-627

36. AIFA. Zitromax-Riassunto delle caratteristiche del prodotto. https://farmaci.agenziafarmaco.gov.it/bancadatifarmaci/cerca -per-principio-attivo?princ_att=Azitromicina. Accessed 4 Aug 2020

37. EMA. Relzosta-Annex I-Summary of product characteristics. https://www.emaeuropaeu/en/documents/product-informatio n/rezolsta-epar-product-information_enpdf. Last accessed: 04 August 2020

38. EMA. Roactemra-Annex I-Summary of product characteristics. https://www.emaeuropaeu/en/documents/product-informatio n/roactemra-epar-product-information_enpdf. Last accessed: 04 August 2020

39. Das EM, Mohan D (1981) Chloroquine-related depression. Indian J Psychiatry 23(2):184-185

40. Lovestone S (1991) Chloroquine-induced mania. Br J Psychiatry: J Mental Sci 159:164-165

41. Bogaczewicz A, Sobow T, Bogaczewicz J, Bienkowski P, Kowalski J, Wozniacka A (2016) Chloroquine-induced subacute paranoid-like disorder as a complication of dermatological treatment. Int J Dermatol 55(12):1378-1380 
42. Bogaczewicz J, Sobow T, Bogaczewicz A, Robak E, Bienkowski P, Sysa-Jedrzejowska A et al (2014) Exacerbations of bipolar disorder triggered by chloroquine in systemic lupus erythematosus-a case report. Lupus 23(2):188-193

43. Emmanuel S, Ostlundh L (2020) Psychiatric adverse events with hydroxychloroquine during COVID-19 pandemic. Asian J Psychiatry 20(54):102203

44. Bitta MA, Kariuki SM, Mwita C, Gwer S, Mwai L, Newton C (2017) Antimalarial drugs and the prevalence of mental and neurological manifestations: a systematic review and meta-analysis. Welcome Open Res 2:13

45. Sato K, Mano T, Iwata A, Toda T (2020) Neuropsychiatric adverse events of chloroquine: a real-world pharmacovigilance study using the FDA Adverse Event Reporting System (FAERS) database. Biosci Trends 14(2):139-143

46. Mascolo A, Berrino PM, Gareri P, Castagna A, Capuano A, Manzo C et al (2018) Neuropsychiatric clinical manifestations in elderly patients treated with hydroxychloroquine: a review article. Inflammopharmacology 26(5):1141-1149

47. Turjanski NLGG (2005) Psychiatric side-effects of medications: recent developments. Adv Psychiatr Treat 11:58-70

48. Winston A, Fatkenheuer G, Arribas J, Hill A, van Delft Y, Moecklinghoff C (2020) Neuropsychiatric adverse events with ritonavir-boosted darunavir monotherapy in HIV-infected individuals: a randomised prospective study. HIV Clin Trials 11(3):163-169

49. Pfefferbaum B, North CS (2020) Mental health and the Covid-19 pandemic. New England J Med 383(6):510-512

50. Ravaldi C, Wilson A, Ricca V, Homer C, Vannacci A (2020) Pregnant women voice their concerns and birth expectations during the COVID-19 pandemic in Italy. Women Birth: J Australian College Midwives

51. Matvienko-Sikar K, Meedya S, Ravaldi C (2020) Perinatal mental health during the COVID-19 pandemic. Women Birth: J Australian College Midwives 33(4):309-310

52. FDA. PLAQUENIL® HYDROXYCHLOROQUINE SULFATE, USP. https://www.accessdatafdagov/drugsatfda_docs/label /2007/009768s041lblpdf. Last accessed: 04 Agust 2020

53. Lin L, Jiang X, Zhang Z, Huang S, Zhang Z, Fang Z et al (2020) Gastrointestinal symptoms of 95 cases with SARS-CoV-2 infection. Gut 69(6):997-1001

Publisher's Note Springer Nature remains neutral with regard to jurisdictional claims in published maps and institutional affiliations. 